\title{
Microbial Agents Responsible for Diarrheal Infections in Flood Victims: A Study from Karachi, Pakistan
}

\author{
Shazia Tabassum Hakim¹, Farkhanda Afaque1, Sumaira Javed2, Shahana Urooj Kazmi ${ }^{3}$, \\ Sayyada Ghufrana Nadeem² \\ ${ }^{1}$ Virology \& Tissue Culture Laboratory, Department of Microbiology, Jinnah University for Women, Karachi, \\ Pakistan \\ ${ }^{2}$ Mycology Research \& Reference Laboratory, Department of Microbiology, Jinnah University for Women, \\ Karachi, Pakistan \\ ${ }^{3}$ I.I.D.R.Lab., Department of Microbiology, University of Karachi, Karachi, Pakistan \\ Email: shaz2971@yahoo.com
}

Received 11 October 2013; revised 12 February 2014; accepted 19 February 2014

Copyright (C) 2014 by authors and Scientific Research Publishing Inc.

This work is licensed under the Creative Commons Attribution International License (CC BY).

http://creativecommons.org/licenses/by/4.0/

Open Access

\section{Abstract}

The present study was aimed to determine the frequency of water borne diarrheal infections and gastroenteritis in two of the flood affected camps of Karachi and nearby areas. Each year approximately, 579,732 people are adversely affected by this phenomenon, putting Pakistan 9th in terms of flood-affected countries worldwide. Patients and Methods: All patients suffering from diarrhea (more than 3 stools per day for the last 2 days), abdominal pain, vomiting or fever who were residing in the camps were included in the study. After taking consent, a fresh stool sample for $D / R$ and $\mathrm{C} / \mathrm{S}$, and $5 \mathrm{ml}$ of venous blood sample for CP and ALT and other viral markers were collected from each patient suffering from any of the symptoms like jaundice, diarrhea, vomiting, fever and abdominal pain during past 2 - 3 days. Direct microscopy of the stools was done to see any protozoal or bacterial infection. Culture of stool was also set up simultaneously. Hemoglobin \% age was noted for each patient. Serology of Hepatitis E and A virus using ELISA (Anti HEV-IgM, and anti HAV IgM) was done in those with more than 2 times raised ALT level. Results: A total of 500 samples collected from refugee camps of flood affected areas near Karachi were included in this study. All patients were mal nourished, having below normal $\mathrm{Hb} \%$ ages, and were suspected cases or patients of diarrhea with elevated ALT (Alanine Transaminase) values. Occult blood was found positive in $40 \%$ (200) specimens; protozoa were also seen i.e., trophozoit stage of Giardia lamblia in $45 \%$ (225) of specimens; Entamoeba coli in 95\% (475) and Balantidium coli in 20\% (100) of stool specimens, while cyst forms of Entamoeba histolytica were present in $35 \%$ (175) specimens. Bacteriological analysis showed high bacterial prevalence of $E$. coli with $63 \%$ (315), followed by Enterobacter specie with $55 \%(275)$, then $20 \%(100)$ and $12 \%(60)$ of Klebseilla oxytoca and Klebseilla 
pneumoniae respectively. Proteus vulgaris and Citrobacter freundii found in the same ratio of $8 \%$ $(40,39)$ with $2 \%(10)$ specimens of no microbial growth. Overall $<0.05 \mathrm{P}$ value and $95 \%$ of confidence interval level was observed. Further serological evidences for water associated viral hepatitis revealed 4\% (20) positive specimens for anti-HEV IgM antibodies, and $2.6 \%$ (13) positive specimens of anti-HAV IgM antibodies. Conclusion: The present study reveals the presence of HEV and HAV associated viral diarrhea along with the presence of protozoal and bacterial infections in the flood relief camps. It is suggested that there is a strong need of natural disaster associated awareness program for general population in order to minimize the mortality and morbidity ratio associated with diseases, which can be easily controlled by managing proper sanitary conditions and supply of safe and clear water.

\section{Keywords}

\section{Flood Camps, Diarrhea, Mal Nourishment, General Awareness, Sanitation}

\section{Introduction}

Sources of drinking water supply in the world as well as in the Pakistan are mostly surface and ground waters. Surface waters are likely to be contaminated by sewage which often contains harmful chemicals, nutrients, disease causing micro-organisms in addition to dissolved material and bits of solid matter such as human waste and garbage. Other reasons for rise in water born outbreaks are increasing vulnerable populations, political upheaval and high numbers of refugees in developing countries. Natural disasters such as flooding and droughts due to climatic changes may also affect global water quality.

A report of 2003 stated that water born infections claim 250,000 deaths each year in Pakistan among which Typhoid fever was the leading cause [1] [2]. Around 4,500,000 cases of diarrhea were reported in 2006, 14\% of which were children under the age of five. Consumption of unsafe drinking water and inadequate sanitary conditions also contribute to increase rate of diarrheal infections [3]-[5]. Consumption of safe drinking water can reduce diarrhea and other related diseases in up to $50 \%$ cases. It was reported that about $62 \%$ of Pakistan's urban population and 84\% of the rural population do not treat their water [6], and it was observed from July 1997 to September 1999 that 585 fecal samples of patients with suspected gastroenteritis, referred to the District Headquarter Hospital Gilgit, were tested. Seventy-seven (13.2\%) fecal samples were infected with different strains of Shigella spp., $61 \%$ of which were Shigella dysenteriae, $15.6 \%$ were Shigella flexneri, and $23.4 \%$ were Shigella specie [7]-[9]. During floods, Ministry of Health, Pakistan reported laboratory confirmation of 99 cases of Vibrio cholera 1 in the country which were laboratory-confirmed by the National Institute of Health.

After bacteria, viruses are the leading cause of diarrheal infections which include hepatitis A, E and Rotavirus. Available data indicates that in Pakistan, Hepatitis E virus (HEV) remains highly endemic throughout the year, mainly affecting the adult population [10] [11] and sporadic cases of hepatitis E occurs frequently. A number of mini-epidemics have been reported in Pakistan and most of these have been due to fecal contamination of water supply, including those reported in Karachi in 1985 and 1986 [4] [5]. Other major reported outbreaks of HEV in Pakistan were 250 cases reported in an Army battalion in 1972 [12], 3827 cases from general population reported in Islamabad in the year 1993 [13]. Another data shows in 1993-1994 36,705 individuals were affected, and the attack rate was $16.3 \%$. The breakdown in water treatment was associated with these outbreaks. The attack rate (AR) was the highest in the age group 11 - 30 (15.3\%), and the AR among pregnant women was even higher, $21.6 \%$. The case fatality rate among non pregnant women was $11.4 \%$ [13] [14], 600 military patients reported in Lahore in 1995 [15]-[17], while 37 out of 65 pregnant women admitted in Karachi in the year 2001 were positive for HEV infections [15] [18] [19].

In the light of this background, this project has a great impact on the public health of Pakistan. It is evident that most of the epidemics of HEV infection were caused by consumption of water that was polluted by faeces. These epidemics could have been avoided if proper measures had been followed. Reason is same, that is: someone's faeces find their way to someone's mouth. The seed (virus) is present, the soil is fertile and the environment is conducive to epidemics of HEV and other water associated infections in much of the developing world and, paticularly in flood affected areas of Pakistan. Preventable infections like water associated bacterial, proto- 
zoal and viral infections, specifically HEV are a major cause of health related issues and disabilities in socioeconomically disadvantaged areas of Pakistan. Improved water supply, wastewater and drinking water treatment using a multiple barrier approach and adequate protection of distribution systems are required to reduce the risk of infectious waterborne diseases. Bacterial and protozoal infections have drugs for treatment while there is no anti-viral drug or commercial vaccine available against HEV. Improvement of personal hygiene and ensuring the supply of safe drinking water remain important to guard against this virus. Although flood hit the area about 2 years ago, the victims are still residing in the camps and struggling for getting basic necessities like health, hygiene and food. They are forced to consume the water available in their surroundings and are therefore at high risk of developing serious water associated disorders like diarrhea (protozoal/bacterial/viral), and hepatitis A virus or HEV. This study report highlights the disease occurence in the camps and also aims to guide the policy makers/decion makers in taking steps to control it [20]-[22].

\section{Methodology}

\subsection{Sample Size: 500 Samples}

Inclusion Criteria: All cases lived in the camps for the past one month or over and presented with vomiting, diarrhea (more than 2 - 3 stools per day for the last 2 days) with or without fever, or those with jaundice were included in the study.

Exclusion Criteria: Patients with less than 2 stools per day, those who have taken antibiotics for some cause in the past week.

Specimens: Once identified as the potential case, the patients were examined by a qualified doctor, who had examined the case and filled the questionnaire and confirmed the inclusion in the study. After taking informed signed consent, stool and blood samples were collected at the camp.

Media/Reagents and Instruments: Eosine Methylene Blue Agar (EMB); (Oxoid), MacConkey's Agar (Oxoid), Tripple Sugar Iron Agar (TSI); (Oxoid), IMViC (Indole (Merck), Methyle Red (Merck), Voges-Proskauer (Merck), and Citrate Agar (Oxoid) ), Enzyme Linked Immunosorbent Assay (EIA) kits for Anti-HEV-M (i.e. Anti Hepatitis E virus Immunoglobulin M) \& HAV-M (i.e. Anti Hepatitis A virus Immunoglobulin) (DS), Sysmex-KX-21 hematology analyzer, microlab 200 biochemistry analyzer.

\subsection{Stool Sample Collection /Detailed Report (D/R)/ and Culture}

Fresh stool sample collected in a sterile container, having a preservative $0.033 \mathrm{M}$ phosphate buffer mixed with equal volumes of glycerol \& transferred to the laboratory at Jinnah University for Women (JUW) within an hour or two, and run for Detail report (D/R) and Culture and Sensitivity (C/S) to check bacterial or/and protozoal infection. Laboratory analysis included microscopic examination and microbiologic tests. The stool samples were examined physically for color, consistency, and the presence of mucus, and for hidden (occult) blood.

The $\mathrm{pH}$ of the stool was also measured. Before proceeding for $\mathrm{D} / \mathrm{R}$ the specimen were streaked on EMB agar (Oxoid) and MacConkey's agar (Oxoid). After 24 hours of incubation colonial confirmation and identification of bacterial colonies was carried out by biochemical findings on IMViC panel and TSI agar (Oxoid) slants.

\subsection{Blood Sample Collection}

A total of $5 \mathrm{ml}$ of blood has been taken from each patient and analyzed for viral antibodies in sera, for complete blood picture (hemoglobin, red cell count, total and differential white cell count, hematocrit, platelet count, mean cell volume, mean cell hemoglobin concentration) using a Sysmex-KX-21 hematology analyzer (S. Ejazuddin \& Company, Pakistan), and biochemical screening (total bilirubin, direct bilirubin, Alanine transaminase (ALT), Aspartate transaminase (AST) and alkaline phosphatase) by using a microlab 200 analyzer (Merck, Germany), (Note: The processed samples for HEV or HAV have an ALT of over two times the upper limit of normal value of 45 to 56 IU/L). Anti-HEV-IgM \& Anti-HAV-IgM antibodies were measured using ELISA.

\section{Results}

A total of $\mathrm{N}=500$; stool and blood specimens were collected from flood victims residing in camps near Karachi city, including: $\mathrm{n}_{1}=275$ males; $\mathrm{n}_{2}=130$ females; and $\mathrm{n}_{3}=95$ children. The suspected individuals were selected according to our decided inclusion criteria. 
Initially, stool samples were collected and processed for D/R and observed that out of 500 samples $29.4 \%$ (147) showed yellowish brown color, whereas 36\% (180) were Brown, and 34\% (170) were Brownish black in color. Consistency of stool was observed as 75\% (375) semisolid form and 25\% (125) were thin. Occult blood was positive in $40 \%$ (200) samples (Table 1 ).

Direct microscopic evaluation of gram's iodine preparations of stool showed that protozoa were also present in majority of specimens i.e., trophozoits of Giardia lamblia were seen in $45 \%$ (225), Entamoeba coli were present in 95\% (475), and Balantidium coli were seen in 20\% (100), while cyst forms of Entamoeba histolytica were present in 35\% (175) of the test samples (Table 1).

For Bacteriological analysis samples were streaked on standard differential and selective bacterial growth medium i.e., MacConkey's and EMB agar (Eosine methylene blue agar) (Oxoid) in order to enhance the growth of Gram negative organisms. Upon isolation; further identification was carried out by microscopy (gram's staining), IMViC and TSI (Triple sugar iron agar) slants (Oxoid). The results revealed the presence of Gram negative organisms with a high ratio of E. coli i.e. 63\%, Enterobacter specie about 55\% and Klebseilla oxytoca and Klebseilla pneumoniae with a ratio of $20 \%$ and $12 \%$ respectively. Proteus vulgaris and Citrobacter freundii were found in almost same proportion of $8 \%$ with $2 \%$ of specimens with no growth (Table 2 and Table 3 ).

On the other hand blood samples of same 500 individuals were screened for the hemoglobin percentage, and presence of malaria parasite. It was noted that all individuals included in this study had below average hemoglobin percentage, and a total of 163 blood samples having ALT values of $100 \mathrm{IU} / \mathrm{L}$ or more (i.e. having ALT of over two times the upper limit of normal value of 45 to $56 \mathrm{IU} / \mathrm{L}$ ), were further selected to check for the presence

Table 1. Stool D/R.

\begin{tabular}{cccc}
\hline & & Stool D/R & \\
\hline & Total Number of Sample: $\mathbf{5 0 0}$ & & \\
\hline & Stool Characteristic & Number of Sample & Total Percentage \\
\hline \multirow{2}{*}{ Color } & Yellowish Brown & 147 & $29.4 \%$ \\
& Brown & 180 & $36 \%$ \\
Consistency & Brownish Black & 170 & $34 \%$ \\
& Semi Solid & 375 & $75 \%$ \\
Occult Blood & Liquid/Thin & 125 & $25 \%$ \\
& Positive & 200 & $40 \%$ \\
Protozoa & Giardia lamblia & 225 & $45 \%$ \\
& Entamoeba coli & 475 & $95 \%$ \\
\hline \multirow{2}{*}{ Cyst } & Balantidium coli & 100 & $20 \%$ \\
\hline
\end{tabular}

Table 2. Bacteriological isolates from stool sample.

\begin{tabular}{|c|c|c|c|c|c|c|c|c|}
\hline \multirow{2}{*}{ Organism Identified } & \multirow{2}{*}{$\begin{array}{l}\text { Microscopic } \\
\text { Observation }\end{array}$} & \multirow{2}{*}{$\begin{array}{c}\text { MacConkey’s } \\
\text { Agar }\end{array}$} & \multirow{2}{*}{ EMB Agar } & \multirow{2}{*}{ IMViC } & \multicolumn{4}{|c|}{ TSI Agar } \\
\hline & & & & & Butt & Slant & Gas & $\mathrm{H}_{2} \mathrm{~S}$ \\
\hline E. coli & Gram-ve, Scattered Rods & Pink Colonies & Black with Metallic Shines & $\mathrm{s}++--$ & A & A & + & + \\
\hline Enterobacter Sp. & Gram-ve, Scattered Rods & Pink Colonies & Dark Color Colonies & --++ & A & A & - & - \\
\hline Klebseilla oxytoca & Gram-ve, Scattered Short Rods & Pink Colonies & Dark Color Colonies & +-++ & A & A & + & - \\
\hline K. pneumoniae & Gram-ve, Scattered Short Rods & Pink Colonies & Dark Color Colonies & --++ & A & A & + & - \\
\hline Proteus vulgaris & Gram-ve, Scattered Rods & Colorless Colonies & Colorless Colonies & $++--1+$ & A & A & $\mathrm{V}$ & + \\
\hline Citrobacter freundii & Gram-ve, Scattered Rods & Pink Colonies & Dark Color Colonies & -+-+ & A/Alk & A & + & + \\
\hline
\end{tabular}

Key: A = Acidic, Alk = Alkaline. 
Table 3. Sample variance and standard deviation of the isolates.

\begin{tabular}{ccc}
\hline \multirow{2}{*}{ Organism Identified } & \multicolumn{2}{c}{ Total \# of Samples = 500 (a) } \\
\cline { 2 - 3 } E. coli & $\begin{array}{c}\text { Number of Positive Samples for Each Organism } \\
\left(\mathrm{b}=\mathrm{b}_{1}+\mathrm{b}_{2}+\mathrm{b}_{3}+\mathrm{b}_{4}+\mathrm{b}_{5}+\mathrm{b}_{6}\right)\end{array}$ & Percentage $=\mathrm{b}_{\mathrm{x}} / \mathrm{a} \times 100$ \\
Enterobacter Sp. & 315 & $63 \%$ \\
Klebseilla oxytoca & 275 & $55 \%$ \\
K. pneumoniae & 100 & $20 \%$ \\
Proteus vulgaris & 60 & $12 \%$ \\
Citrobacter freundii & 40 & $8 \%$ \\
No Growth & 39 & $8 \%$ \\
\hline
\end{tabular}

of anti-HEV IgM antibodies and anti-HAV IgM antibodies.

Out of these 163, we found 20 samples positive for anti-HEV IgM antibodies and 13 samples positive for anti-HAV IgM antibodies. So, it was estimated that out of 500 test individuals only $4 \%$ were carrying the antiHEV IgM antibodies and 2.6\% were having anti-HAV IgM antibodies respectively. This indicates that about $4 \%$ of the individual included in the study were infected with HEV infection and a low percentage with $2.6 \%$ occurrence showed current infection of HAV, with no significant values ( $>0.05 \mathrm{P}$ value) and confidence interval level (Tables 4-6). Raised ALT level among rest of the 130 samples out of 163 could be because of some other reasons like protozoal infections, some injury or physical disorder.

Overall health condition of male participants was comparatively better than the females and children and main cause of this illness was found to be associated with unavailability of clean water. Same water which cannot be recommended for even washing purpose; was there in the camps for drinking and cooking purposes. Because of shortage of water the victims were not able to take bath, wash their hands and their utensils properly on regular basis as a result they were multiplying the spread of different diseases in those camps.

\section{Discussion}

The risk for diarrheal disease outbreaks following natural disasters is higher in developing countries than in industrialized countries [22] [23]. These risk factors after disasters are associated primarily with the population displacement, availability of safe water and sanitation facilities, degree of crowding, underlying health status of the population, and the availability of healthcare services all interact within the context of the local disease ecology to influence the risk for communicable diseases and death in the affected population [24].

These natural disasters like earthquake and flood predispose the classical water associated infections as the sewerage lines and water lines gets contaminate with each other and leads to many water borne infections [25]. That is the reason why water borne diseases and the diseases transmitted by fecal oral route are always a main concern.

Besides a number of bacteria (especially the members of family enterobacteriaceae like E. coli and Enterobacter sp.) Hepatitis A and E viruses are also transmitted by the fecal-oral route, in association with lack of access to safe water and sanitation. Hepatitis A is endemic in most of the developing countries, and most children are exposed and develop immunity at an early age. As a result, the risk for large outbreaks is usually low in these settings. In case of hepatitis E-endemic areas, outbreaks frequently follow heavy rains and floods; the illness is generally mild and self-limited, but in pregnant women case-fatality rates can reach $25 \%$ [26].

HEV is considered as typically water borne liver associated disease which is a non A non B virus and was identified by Balyan et al. [27] [28]. Under developing countries while mainly focusing on Pakistan has history of few great endemic cases in these regions for hepatitis E virus (HEV) infection. Abb-2B \& Sar-55 strains are the most common endemic strains of HEV in Pakistan [29]. In addition to the mal nutrition, marriages in early age leading pregnancy are other major causes of HEV infection; as a result, chances of mother to fetus transmission of these viruses also increases [30].

According to WHO; in Muzaffarabad, Pakistan, an outbreak of acute watery diarrhea occurred in an unplanned, poorly equipped camp of 1800 persons after the 2005 earthquake. The outbreak involved $>750$ cases, 
Table 4. Chi-square test.

\begin{tabular}{cccc}
\hline & Observed N & Expected N & Residual \\
\hline E. coli & 315 & 117.3 & 197.7 \\
Enterobacter sp. & 276 & 117.3 & 158.7 \\
K. oxytoca & 101 & 117.3 & -16.3 \\
K. pneumoniae & 40 & 117.3 & -77.3 \\
Proteus vulgaris & 40 & 117.3 & -77.3 \\
C. freundii & 39 & 117.3 & -78.3 \\
No Growth & 10 & 117.3 & -107.3 \\
Total & 821 & & \\
\hline
\end{tabular}

Table 5. Anti-HEV IgM \& Anti-HAV IgM antibodies detected from the blood samples of the same participants.

\begin{tabular}{cccc}
\hline Total Number of Samples & Anti HEV-IgM Abs. & Anti HAV-IgM Abs. & Total $\%$ age $=+$ ve Sample/total number of sample $\times 100$ \\
\hline 500 & 20 & 13 & $4 \%$ \\
500 & - & $2.6 \%$ \\
\hline
\end{tabular}

Table 6. Anti HEV IgM \& HAV IgM detected from samples.

\begin{tabular}{ccccc}
\hline & & \multicolumn{2}{c}{ Test } & Total \\
\cline { 3 - 5 } & & Positive & Negative & 500 \\
Antibodies & HEV IgM & 20 & 480 & 500 \\
Total & HAV IgM & 13 & 487 & 967 \\
\hline
\end{tabular}

mostly in adults, and was controlled after adequate water and sanitation facilities were provided. Same report says that after the 2005 earthquake in Pakistan, sporadic hepatitis E cases and clusters were common in areas with poor access to safe water and over 1200 cases of acute jaundice, many confirmed as hepatitis E, occurred among the displaced [31].

Later on in August 2010, Pakistan suffered one of the most severe floods in its history. These floods are the most frequently occurring and damaging natural hazards in the country, and unfortunately, of all population who are affected by natural hazards, $90 \%$ are subjected to flooding [32].

According to BBC News, 2010 (http://www.bbc.co.uk/news/world-south-asia-10896849) while covering updates on flood in Pakistan; it was mentioned that flood affected regions serve as ideal breeding grounds for pathogens, leading to the spread of diseases. It was also said that the poor standards of hygiene in camps set up for the floods victims also contribute to this, and hence it is essential that those involved in relief efforts should be aware of the epidemiology of diseases that have historically seen a sudden upsurge after natural disasters.

In a literature review by Baqir $\mathrm{M}$ et al., published in 2012: seven major diseases were identified to increase substantially in the aftermath of natural disasters; especially after flood and earthquakes. Which were then classified into acute and sub-acute settings? Diarrhea, skin \& eye infections and leptospirosis were identified in the acute settings while malaria, leishmaniasis, respiratory infections and hepatitis were identified in the sub-acute settings [33].

Keeping this whole in mind our research group at Department of Microbiology, Jinnah University for Women, Karachi, came up with a proposal to conduct a research based survey of flood victims of 2010 flood in Sindh, Pakistan.

Sewage water, stagnant pools of water in and outside the camps, drainage material contaminated with animal's excreta, children and adults walking bare foot, while children playing in same contaminated water were all 
the contributing factors for spread of variety of diseases.

As per our decided criteria we included only mal nourished and suspected individuals in this study. Direct Microscopic examination followed by Bacteriological and serological analysis of stool and blood samples was done to detect the water associated diarrheal disorders among flood victims. According to our findings the sufferers were facing single or multiple infections of variety of protozoa and bacteria including Giardia lamblia (45\%), Entamoeba coli (95\%), Balantidium coli (20\%), cysts of Entamoeba histolytica (35\%), E. coli (63\%), Enterobacter sp. (55\%), Klebseilla oxytoca (12\%), and Klebseilla pneumoniae (20\%), Proteus vulgaris (8\%), and Citrobacter freundii (8\%). Overall $\mathrm{P}$ value was $<0.05$ and $95 \%$ of confidence interval level was there. Serological analysis for water associated viral hepatitis revealed $4 \%$ (20) positive specimens for anti-HEV IgM antibodies, and 2.6\% [13] positive specimens of anti-HAV IgM antibodies.

It is a fact that floods can potentially increase the spread and transmission of various infections; especially those related to consumption of contaminated water supplies, and this problem is enhanced many times in countries with limited resources and low socio economic conditions. Hence, it is suggested that as the relief efforts in natural disasters like flood hits a country like Pakistan, all the officials and care givers should brace themselves for an outbreak [34] [35]. It is very important to manage proper sanitary and hygienic provisions in the flood affected regions. It is also worth mentioning that there is no replacement of awareness, and awareness of these conditions i.e. natural disasters associated disease outbreaks; is really something that is lacking in our general population. If we may start working on creating awareness about these natural disasters associated outbreaks in advance through our social media, in our institutions: colleges, universities, schools, and at general public level, we believe this would significantly reduce the morbidity and mortality associated with these disasters [35] [36].

It is also very important to mention that there are very few studies available on Hepatitis A and Hepatitis E associated viral diarrhea from Pakistan that is why there is an urgent need to have an extended study on prevalence of these viruses and related infections in Pakistan [36] [37].

\section{Conclusions}

It is a documented fact that Pakistan is ranked 9th in terms of flood-affected countries worldwide. In this study we concluded that contaminated water associated infections are still a health problem in Pakistan including protozoal, bacterial and viral diseases like Hepatitis A \& E virus infection, which is a classical water associated disease, especially in the time duration when natural catastrophe has occurred in such developing countries. Results of this study emphasized presence of a variety of protozoa, bacteria and viruses associated with contaminated water supplies and suggested for a more elaborated study for appropriate surveillance. It is also requested that these kinds of studies demand immediate approvals in order to minimize the escape of study participants and change in specific situations, which may help in appropriate conclusions and timely decisions.

Although we know that for the majority of the world's population, particularly in resource limited low socioeconomic developing countries, the health benefits of clean water and "flush" toilets are far from reach, we are also aware that contaminated or untreated water plays a main role as a vehicle in enteric pathogen transmission, and only a sanitary revolution can help us to reduce the burden of these sporadic outbreaks, especially after natural disasters.

\section{Acknowledgements}

The current study project was financially supported by the grant (Ref \# 4-22-1/10/Flood/RDC/JUW/1824; Dated 02-03-2012) from Pakistan Medical Research Council, Islamabad, Pakistan. We are grateful to Mr. Wajeehuddin Ahmed, Chancellor JUW, and Prof. Dr. Naeem farooqui Vice Chancellor, JUW for the moral and administrative support we received throughout the study period.

\section{References}

[1] http://english.ntdtv.com/ntdtv_en/ns_asia/2010-08-19/230444340731.html

[2] Peron, J.M., Menusy, J.M., Izopet, J. and Vinel, J.P. (2006) Hepatitis E Virus: An Emerging Disease. Sante, 16, 239243.

[3] Khuroo, M.S. (1980) Study of an Epidemic of Non-A, Non-B Hepatitis. Possibility of Another Human Hepatitis Virus Distinct from Post-Transfusion Non-A, Non-B Type. American Journal of Medicine, 68, 818-824.

http://dx.doi.org/10.1016/0002-9343(80)90200-4 
[4] Malik, I.A., et al. (1988) Epidemics of Non-A, Non-B Hepatitis in Pakistan. Tropical Doctor, 18, 99-101.

[5] Ministry of Health, Pakistan (2010) Priority Disease Report (2005-2006). http://www.statpak.gov.pk/depts/fbs/statistics/social_statistics/priority_disease_report.pdf

[6] http://www.usaid.gov/stories/pakistan/fp_pakistan_water.html

[7] Bradley, D.W. (1990) Enterically-Transmitted Non-A, Non-B Hepatitis. British Medical Bulletin, 46, 442-461.

[8] Parashar, U.D., Gibson, C.J., Bresee, J.S. and Glass, R.I. (2006) Rotavirus and Severe Childhood Diarrhea. Emerging Infectious Diseases, 12, 304-306. http://dx.doi.org/10.3201/eid1202.050006

[9] Parashar, U.D., Hummelman, E.G., Bresee, J.S., Miller, M.A. and Glass, R.I. (2003) Global Illness and Deaths Caused by Rotavirus Disease in Children. Emerging Infectious Diseases, 9, 565-572. http://dx.doi.org/10.3201/eid0905.020562

[10] Parashar, U.D., Burton, A., Lanata, C., et al. (2009) World Health Organization Estimates of the Global Mortality from Rotavirus in Children in the Year 2004. The Journal of Infectious Diseases, in Press.

[11] Khan, R.U., Beeching, N.J., Tong, C.W., et al. (1995) Sporadic Hepatitis E in Pakistan. Annals of Tropical Medicine and Parasitology, 89, 95-97.

[12] Akram, M. (1975) A Study of Epidemic Infectious Hepatitis in the Field. CENTO (Central Treaty Organization) Medical Conference Papers.

[13] Rab, M.A., Bile, M.K., Mubarik, M.M., et al. (1997) Water-Borne Hepatitis E Virus Epidemic in Islamabad, Pakistan: A Common Source Outbreak Traced to the Malfunction of a Modern Water Treatment Plant. The American Journal of Tropical Medicine and Hygiene, 57, 151-157.

[14] Rab, M.A., et al. (1997) Water-Borne Hepatitis E Virus Epidemic in Islamabad, Pakistan: Common-Source Outbreak Traced to the Malfunction of a Modern Water Plant. The American Journal of Tropical Medicine and Hygiene, 57, 151-157.

[15] Malik, I.A. and Tariq, W.U.Z. (1995) The Prevalence and Pattern of Viral Hepatitis in Pakistan. Journal of the College of Physicians and Surgeons Pakistan, 5, 2-3.

[16] Shams, R., Khero, R.B., Ahmed, T. and Hafiz, A. (2001) Prevalence of Hepatitis E Virus (HEV) Antibody in Pregnant Women of Karachi. Journal of Ayub Medical College Abbottabad, 13, 31-35.

[17] Saeedi, M.I., Mahmood, K., Amanullah, Ziauddin, M., Ilyas, N. and Zarif, M. (2004) Frequency and Clinical Course of Hepatitis E in Tertiary Care Hospitals. Journal of the College of Physicians and Surgeons Pakistan, 14, 527-529.

[18] Bryan, J.P., Iqbal, M., Tsarev, S., et al. (2002) Epidemic of Hepatitis E in a Military Unit in Abbotrabad, Pakistan. The American Journal of Tropical Medicine and Hygiene, 67, 662-668.

[19] Alavian, S.M. (2007) Hepatitis E Virus Infection: A Neglected Problem in Our Region. Hepatitis Monthly, 7, 1191121.

[20] Van Cuyck-Gandré, H., Zhang, H.Y., et al. (1995) Partial Sequence of HEV Isolates from North Africa and Pakistan: Comparison with Known Sequences. In: Buisson, Y., Coursaget, P. and Kane, M., Eds., Enterically-Transmitted Hepatitis Viruses, La Simarre, Tours, 301-310.

[21] Van Cuyck-Gandré, H., Zhang, H.Y., et al. (1997) Characterization of Hepatitis E Virus (HEV) from Algeria and Chad by Partial Genome Sequence. Journal of Medical Virology, 53, 340-347. http://dx.doi.org/10.1002/(SICI)1096-9071(199712)53:4<340::AID-JMV5>3.0.CO;2-7

[22] Noji, E. (1997) Public Health Consequences of Disasters. Oxford University Press, New York.

[23] Ahern, M., Kovats, R.S., Wilkinson, P., Few, R. and Matthies, F. (2005) Global Health Impacts of Floods: Epidemiologic Evidence. Epidemiologic Reviews, 27, 36-46. http://dx.doi.org/10.1093/epirev/mxi004

[24] Watson, J.T., Michelle, G. and Maire, A.C. (2007) Epidemics after Natural Disasters. Emerging Infectious Diseases, 13, 1.

[25] Krawezynski, K., Kamili, S. and Aggarwal, R. (2001) Global Epidemiology and Medical Aspects of Hepatitis E. Forum (Genova), 11, 166-179.

[26] Aggarwal, R. and Krawczynski, K. (2000) Hepatitis E: An Overview and Recent Advances in Clinical and Laboratory Research. Journal of Gastroenterology and Hepatology, 15, 9-20.

[27] Balayan, M.S. (1997) Type E Hepatitis: State of the Art. International Journal of Infectious Disease, 2, 113-120. http://dx.doi.org/10.1016/S1201-9712(97)90093-X

[28] Balayan, M.S., Andjaparidze, A.G., Savinskaya, S.S., et al. (1983) Evidence for a Virus in Non-A, Non-B Hepatitis Transmitted via the Fecal-Oral Route. Intervirology, 20, 23-31. http://dx.doi.org/10.1159/000149370

[29] Quiroga, J.A., Cotonat, T., Castillo, I., Carreno, I. and Carreno, V. (1996) Hepatitis E Virus Seroprevalance in Acute Viral Hepatitis in a Developed Country Confirmed by a Supplemental Essay. Journal of Medical Virology, 50, 16-19. http://dx.doi.org/10.1002/(SICI)1096-9071(199609)50:1<16::AID-JMV4>3.0.CO;2-W 
[30] Iqbal, T., et al. (2011) Isolation and Characterization of Two New Hepatitis E Virus Genotype 1 Strains from Two Mini-Outbreaks in Lahore, Pakistan. Virology Journal, 8, 94.

[31] World Health Organization Acute Jaundice Syndrome (2006) Weekly Morbidity and Mortality Report.

[32] Haider, N. (2006) Living with Disasters: Disaster Profiling of Districts of Pakistan. National Disaster Management Authority, Islamabad, 65.

[33] Baqir, M., et al. (2012) Infectious Diseases in the Aftermath of Monsoon Flooding in Pakistan. Asian Pacific Journal of Tropical Biomedicine, 2, 76-79.

[34] Schlauder, G.G., Desai, S.M., Zanetti, A.R., Tassopoulos, N.C. and Mushahwar, I.K. (1999) Novel Hepatitis E Virus (HEV) Isolates from Europe: Evidence for Additional Genotypes of HEV. Journal of Medical Virology, 57, $234-251$. http://dx.doi.org/10.1002/(SICI)1096-9071(199903)57:3<243::AID-JMV6>3.0.CO;2-R

[35] Uchida, T. (1992) Hepatitis E: Review. Gastroenterology of Japan, 27, 687-696.

[36] Khan, R.U., Beeching, N.J., Tong, C.W., et al. (1995) Sporadic Hepatitis E in Pakistan. Annals of Tropical Medicine and Parasitology, 89, 95-97.

[37] Meng, X.J., Purcell, R.H., Halbur, P.G., et al. (1997) A Nevel Virus in Swine Is Closely Related to the Human Hepatitis E Virus. Proceedings of the National Academy of Sciences of USA, 94, 9860-9865. http://dx.doi.org/10.1073/pnas.94.18.9860 